\title{
The State of Academic Liaison Librarian Burnout in ARL Libraries in the United States
}

\section{Jennifer Nardine}

This study investigates the incidence and acuteness of occupational burnout in fulltime Association of Research Libraries (ARL) liaison/subject librarians in the United States, using the Maslach Burnout Inventory and Areas of Worklife Survey. Findings show that lack of personal agency is the primary contributor to a sense of burnout and that, while many liaisons feel significant levels of overwork and lack of fair treatment, positive correlation between institutional and personal values runs high regardless of gender, time as a liaison, or time spent at a particular institution. This values relationship, along with a strong sense of personal efficacy, may moderately offset burnout symptoms. Still, findings indicate a need for further study of burnout in the overall academic librarian population, as well as a significant need for change in liaison librarians' professional experiences to ease their reported levels of burnout.

\section{Introduction}

Burnout, a term whose introduction into the realm of research is credited to psychologist Herbert Freudenberger in $1974,{ }^{1}$ has been regularly used to describe workers' need for a vacation, a break, or a change. However, in recent decades "burnout" has come to mean something very specific from the perspectives of psychology and occupational health. Dr. Christina Maslach, Professor Emerita of Psychology at UC Berkeley, along with her colleagues Dr. Wilmar Schaufeli of Leuven University in Belgium and Dr. Michael Leiter of Acadia University in Canada, invigorated the study of burnout-its facets and occurrence-in 1976. ${ }^{2}$ Their studies led to the development of the Maslach Burnout Inventory (MBI), which remains the seminal inventory for evaluating a person's level of burnout, ${ }^{3}$ and Areas of Worklife Survey (AWS), which evaluates a person's fit with their occupation. ${ }^{4}$

The underlying importance of recognizing and relieving burnout is that the syndrome affects an individual's entire life and their personal ecosystem. While more investigation is still needed, initial studies often indicate that:

burnout can actually alter neural circuits in the brain, changes [that] may be responsible for the inability of [persons] experiencing high degrees of burnout to adequately regulate their emotions, a decrease in fine motor function, and diminished ability to shift from one stimulus to another... Burnout seems to be correlated with various 
self-reported indicators of personal dysfunction, including physical exhaustion, insomnia, increased use of alcohol and drugs, and marital and family problems, along with decreased quality of the service relationship ... [low] mood and social behavior, $\ldots$ absenteeism, increased turnover, and decreased job performance. ${ }^{5}$

According to Maslach, "burnout is a syndrome of three types of feelings[:] emotional exhaustion, depersonalization, and low professional efficacy." ${ }^{\prime 6}$ Severity of burnout is calculated by interpreting the MBI scores for these three areas separately, rather than combining them into a single burnout score. ${ }^{7}$

The AWS, also by Leiter and Maslach, is a complementary instrument measuring "the degree of fit, or congruence, between person and environment....The notion of 'fit' is often presumed to predict such outcomes as choice of job/occupation or of organization (entry issues), or adjustment to the job (newcomer issues)." ${ }^{\prime 8}$ By combining burnout levels with employee perceptions of workplace qualities, we gain a better-rounded understanding of employees' overall happiness at work.

This study, the first formal inquiry into liaison librarian burnout in more than a decade, uses slightly modified versions of the MBI and AWS to collect and evaluate levels of academic liaison librarian burnout at ARL libraries in the United States. These modifications were created to incorporate language that is more relevant to librarianship. The principles of the current study remain consistent with those of the original MBI and AWS and are designed to address these specific burnout-related research questions:

- How well do the values of liaison librarians correlate with the values of their profession?

- How pervasive is moderate to severe burnout in this population?

- How do self-identified primary role and level of seniority affect burnout?

- How does service time spent as a liaison affect burnout levels?

- How does service time spent at an organization affect burnout levels?

- Is there a gender effect on liaison librarian burnout?

The researcher developed the above questions based on a combination of professional interest, anecdotal input from the library liaison community, a lack of available information about liaison burnout, and the functionality of the MBI/AWS instrument combination. By addressing the broad question of how frequently statistically measurable burnout in the liaison librarian population occurs, this quantitative data can then be used to provide concrete evidence of the need, or lack thereof, for change in the population's work environment to library and university administration.

More specific purposes of this investigation include the following: a) measure current levels of burnout in liaison librarianship; $b$ ) determine whether factors such as gender, service time at an institution, and personal/work value correlation affect burnout level; and c) increase interest in and awareness of liaison librarian burnout in the academic library community. By establishing a baseline for burnout measurement in this academic population, this study provides academic institutions with useful insights regarding faculty and staff retention and for enhanced work-life balance.

\section{Literature Review}

According to Muheim, burnout as a syndrome has been noted as far back as the Old Testament, ${ }^{9}$ but it was not until a 1953 article discussing low morale among nurses and its effects on pa- 
tient care that the modern study of burnout began. In 1974, Freudenberger's advanced study documented "the gradual energy depletion and loss of motivation ... and commitment" in a group of volunteers at a drug clinic. ${ }^{10}$ Shortly thereafter, Maslach began her extensive study of the phenomenon, collaborating with a variety of colleagues over multiple decades to the present day.

The original MBI, published in 1981, characterizes burnout as "a psychological response to aspects of one's daily experiences." 11

Over the course of her work, Maslach's interests evolved from developing a single instrument to creating population-specific versions. There are currently five versions of the MBI: the MBI-HSS designed for human services professionals; the MBI-HHS(MP), which was adapted for specific use with medical personnel; the MBI-ES for educators; the MBI-GS for use with those occupations outside human services and education; and the MBI-GS(S) for assessing college and university students. ${ }^{12}$

The MBI-HSS combines nine Emotional Exhaustion questions assessing feelings of being "emotionally overextended and exhausted by one's work," five questions measuring Depersonalization as expressed by "an unfeeling and impersonal response towards recipients of one's service, care, treatment or instruction," and eight Personal Accomplishment items assessing "feelings of competence and successful achievement in one's work with other people."13

\begin{tabular}{|c|c|c|c|c|c|c|c|}
\hline \multicolumn{8}{|c|}{$\begin{array}{c}\text { TABLE } 1 \\
\text { Sample MBI Question addressing Personal Accomplishment with Rating Scale }\end{array}$} \\
\hline \multicolumn{8}{|c|}{$\begin{array}{c}\text { I feel } x . \\
\text { (Example: I feel like a valued employee.) }\end{array}$} \\
\hline How Often? & 0 & 1 & 2 & 3 & 4 & 5 & 6 \\
\hline & Never & $\begin{array}{l}\text { A few } \\
\text { times a } \\
\text { year or less }\end{array}$ & $\begin{array}{l}\text { Once a } \\
\text { month or } \\
\text { less }\end{array}$ & $\begin{array}{l}\text { A few } \\
\text { times a } \\
\text { month }\end{array}$ & $\begin{array}{l}\text { Once a } \\
\text { week }\end{array}$ & $\begin{array}{l}\text { A few } \\
\text { times a } \\
\text { week }\end{array}$ & Every day \\
\hline
\end{tabular}

With regard to reliability and validity, "an analysis of 84 published studies that reported sample-specific reliability estimates for the three MBI scales ${ }^{14}$ found that the reliability estimates for the Emotional Exhaustion scale average in the high .80s; for Depersonalization and Personal Accomplishment, average reliability estimates are in the mid-.70s. The validity of the MBI in its multiple versions has been demonstrated by numerous studies and metaanalytic reviews that confirm hypotheses about the relationships between job attributes and experienced burnout."15

Most recently, Leiter and Maslach have been developing burnout profiles to identify "patterns of the burnout experience, [offering] new [approaches] for understanding both the causes and consequences of burnout and may have implications for the best interventions to prevent or reduce burnout."16

The AWS focuses on "job-person fit" rather than burnout levels. This instrument examines the interaction of a person with their environment, noting that "better fit was assumed to predict better adjustment and less stress." 17 This leads to Leiter and Maslach's hypothesis that "the greater the perceived gap between the person and the job, the greater the likelihood of burnout." 18 
The 28-question AWS assesses six areas of job stress and/or satisfaction: Workload, Control, Reward, Community, Fairness, and Values. While Workload and Values are straightforward, it is important to understand the nuances of the other categories in this assessment. Control “addresses an employee's perceived capacity to influence decisions that affect their work, to exercise professional autonomy, and to gain access to the resources necessary to do an effective job." Reward refers not only to monetary rewards but also to social and intrinsic ones. Community addresses the "overall quality of social interaction at work, including issues of conflict, mutual support, closeness, and the capacity to work as a team," and Fairness includes both issues of general work decisions and perceived levels of mutual respect. ${ }^{19}$

AWS language varies to include both negatively and positively worded questions to avoid potential response bias. Users calculate the subscores for each area described above using a combination of direct and reversed scoring, depending on the positivity or negativity of the question's wording. The six subscores are not combinable but can be reviewed for an overall impression of positive or negative job-person fit. ${ }^{20}$

Like the MBI, the AWS has been tested numerous times for both reliability and validity. During instrument development, "the [AWS] showed consistently high correlations with the three burnout dimensions measured by the $[\mathrm{MBI}] .{ }^{21}$ Accordingly, this researcher chose to use both instruments to evaluate the target population.

When assessing correlation between the two scales, Maslach, Jackson, and Leiter determined that positive AWS scores negatively correlate with Emotional Exhaustion and Depersonalization (but positively correlate with Efficacy) and that the AWS Workload is more closely related to Emotional Exhaustion than the other MBI dimensions and vice versa. ${ }^{22}$

Since the release of the $1981 \mathrm{MBI}$, much research has been done on occupational burnout, notably for helping professions including education, counseling, law enforcement, and nursing, as well as for swaths of the corporate sector. Librarians, however-and academic liaison librarians in particular - have yet to be thoroughly assessed for burnout in a formal or longitudinal way using this instrument.

While the issue of academic librarian burnout arises occasionally, there have been relatively few formal studies of the phenomenon. Mary Ann Affleck surveyed bibliographic instruction (BI) librarians in 1993 and discovered that more than 60 percent of those surveyed suffered from moderate to high burnout levels in at least one dimension of the study. ${ }^{23}$ Deborah Sheesley updated the assessment in 2001, focusing her research on teaching librarians. ${ }^{24}$ Still more recently, a report analyzing the relationship between certain background characteristics and burnout in Greek academic librarians found that age, years in librarianship, and participation in decision-making had low correlation to experienced burnout compared to factors including library setting and policies, time spent in direct contact with patrons, and length of contract. ${ }^{25}$

Another group of studies examines the librarian population as a whole. While Workplace Stress in Libraries: A Case Study, ${ }^{26}$ Emotional Labour in Librarians' Instruction Work, ${ }^{27}$ and RoleRelated Stress Experienced by Academic Librarians ${ }^{28}$ also address librarian burnout, they evaluate broader populations. Emotional Labor in Librarianship: A Research Agenda expresses the need for such studies but does not include one. ${ }^{29}$ The 2013 follow-up article examines emotional labor as a factor in burnout and notes the disconnect between what librarians may express versus what they feel; but, again, it focuses on the wider librarian profession. ${ }^{30}$ 
As such, while there has been a relatively steady stream of investigations into librarian well-being, rarely did such studies focus on academic liaisons. Given the continued place of academic libraries as "the heart of the university" ${ }^{31}$ to which reputation liaisons provide a significant contribution, ${ }^{32}$ it is time to closely examine burnout in this population. For the current study, the researcher elected to use the MBI Human Services Survey (MBI-HSS), as it is the original and most frequently used version. ${ }^{33}$

After selecting the MBI and AWS as the assessment tools for the current study, the researcher purchased licenses for 250 access links to this modified survey on the MindGarden platform, which serves both as a secure data gathering and holding location, as well as a means for accessing the survey results for analysis.

To augment the relatability of both instruments for an academic audience, as compared to the original health and human services audience, the researcher requested some minor changes in question wording. Consequently MindGarden, which holds the distribution rights to the MBI and the AWS, modified the question language to refer to "recipients" and "patrons" rather than the original "patients." Six additional demographic questions were included to further distinguish various subgroups within the population:

a. Are you a full- or part-time employee? (included to weed out part-time personnel)

b. What is your level within your organization? (with potential responses: front-line, supervisor, first-tier management, middle management, or upper management)

c. What do you see as your primary job responsibility/focus? (with potential responses: instruction, collections, data management, archives, or other)

d. What do you see as your secondary job responsibility/focus? (with potential responses: instruction, collections, data management, archives, or other)

e. How long have you worked at this organization? (with potential responses: $1=0-6$ months, $2=7-11$ months, $3=1-2$ years, $4=3-5$ years, $5=6-10$ years, $6=11-15$ years, $7=16-20$ years, or $8=21+$ years)

f. How long have you worked in your present position as liaison in this organization? (with potential responses: $1=0-6$ months, $2=7-11$ months, $3=1-2$ years, $4=3-5$ years, $5=6-10$ years, $6=11-15$ years, $7=16-20$ years, or $8=21+$ years)

In interpreting direct burnout findings, the researcher used the scales from the MBI manual. ${ }^{34}$ High scores in Emotional Exhaustion and Depersonalization and low scores in Professional Efficacy correlate with high levels of burnout. Given the instrument's seven-point range, this study defines moderate burnout as scores $\geq 2.5$ and $\leq 3.99$, and significant burnout as scores $\geq 4.00$ for the Emotional Exhaustion and Depersonalization dimensions. Scores of $\geq 2.5$ and $\leq 3.99$ signify moderate burnout, and scores $\leq 2.49$ indicate significant burnout on the Personal Efficacy dimension.

For all dimensions of the AWS, a higher score correlates with a "higher degree of congruence between the workplace and the respondent's preferences." Per the AWS manual, ${ }^{35}$ "each measure has a range of 4.00, from 1.00 (extreme mismatch) to 5.00 (extreme match) with a midpoint at 3.00."

The study population comes from academic libraries within the United States and, within that context, full-time librarians who were identified as department liaisons. Poll recipients were randomly selected from a list of librarians from Association of Research Libraries (ARL) member libraries within the United States. ${ }^{36}$ This set was further narrowed to a pool of 2,069 persons identified as subject selectors, subject specialists, college librarians, or liaisons on their individual university websites in April 2016. 
Once assembled, the pool members were each assigned a randomly generated number, then sorted in numeric order. Invitations to participate were distributed in batches of 250 between May 1 through July 8 of 2016 until all 250 available survey links had been used. From that response pool, the researcher eliminated one survey on the basis of the subject's ineligibility and 73 others that were incomplete, leaving 176 fully complete surveys. At this response rate, 95 percent of the total population lies within a 7.07 percent margin of error. While not ideal, the sample is sufficiently statistically significant to use as a starting point for evaluation.

\section{Findings}

- How well do the values of liaison librarians correlate with the values of their profession? When graphed for range with a highlighted mean for each measure, as shown in figure 1 , the AWS data show clearly that, while there is a notable level of Workload strain, the measure with the lowest mean (thus indicating lowest satisfaction) is Fairness. The other four measures indicate more positive ratings, thus providing a positive trend in attitudes and better job-person fit. When viewed as a whole, this indicates that the people who have elected to work as liaison librarians have strong matches between their personal values and the values and requirements of their profession.

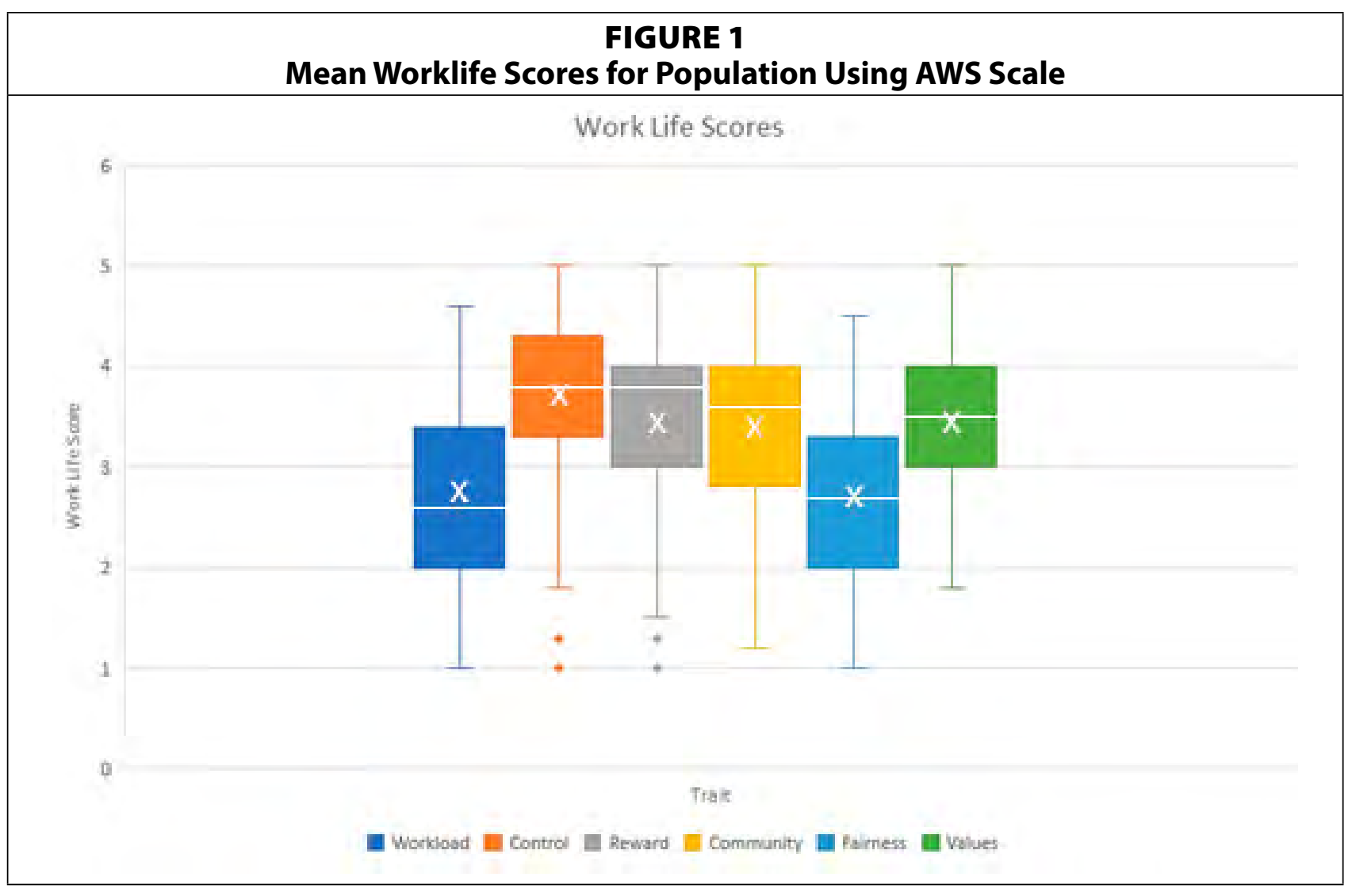

- How pervasive is moderate to severe burnout in this population?

In assessing levels of burnout for the overall population, the researcher considered both the mean worklife scores from the AWS and the three subscores from the MBI. Table 2 indicates the range of both negative (Workload) and positive (other five measures) scores in the AWS for the entire population. 


\begin{tabular}{|l|c|c|c|c|c|c|}
\hline \multicolumn{7}{|c|}{ TABLE 2 } \\
\hline & Workload & Control & Reward & Communication & Fairness & Values \\
\hline Range & $1.0-4.6$ & $1.0-5.0$ & $1.0-5.0$ & $1.2-5.0$ & $1.0-4.5$ & $1.8-5.0$ \\
\hline Mean & 2.723 & 3.715 & 3.464 & 3.400 & 2.683 & 3.442 \\
\hline Median & 2.0 & 3.8 & 3.8 & 3.6 & 2.7 & 3.5 \\
\hline Std. Dev. & 0.844 & 0.835 & 0.858 & 0.819 & 0.800 & 0.655 \\
\hline
\end{tabular}

The MBI responses in table 3 indicate that this population experiences a sense of Personal Accomplishment that outweighs Emotional Exhaustion, based on the low-end values of each factor. Differences between reported Personal Accomplishment and Depersonalization are also evident, as Depersonalization scores range well below the bottom Personal Accomplishment score, while Personal Accomplishment scores exceed the highest reported Depersonalization level.

\begin{tabular}{|l|c|c|c|}
\hline \multicolumn{4}{|c|}{ Averaged scores for entire sample using MBI Scale } \\
\hline & MBI Emotional Exhaustion & MBI Depersonalization & MBI Personal Accomplishment \\
\hline Range & -6.0 & $0.0-5.2$ & $1.8-6.0$ \\
\hline Mean & 2.67 & 1.19 & 4.67 \\
\hline Median & 2.60 & 0.80 & 4.60 \\
\hline Std. Dev. & 1.33 & 1.11 & 0.87 \\
\hline
\end{tabular}

When reviewing the distribution of burnout factors for the entire population, the researcher found trends linking levels of Personal Accomplishment, Depersonalization, and Emotional Exhaustion.

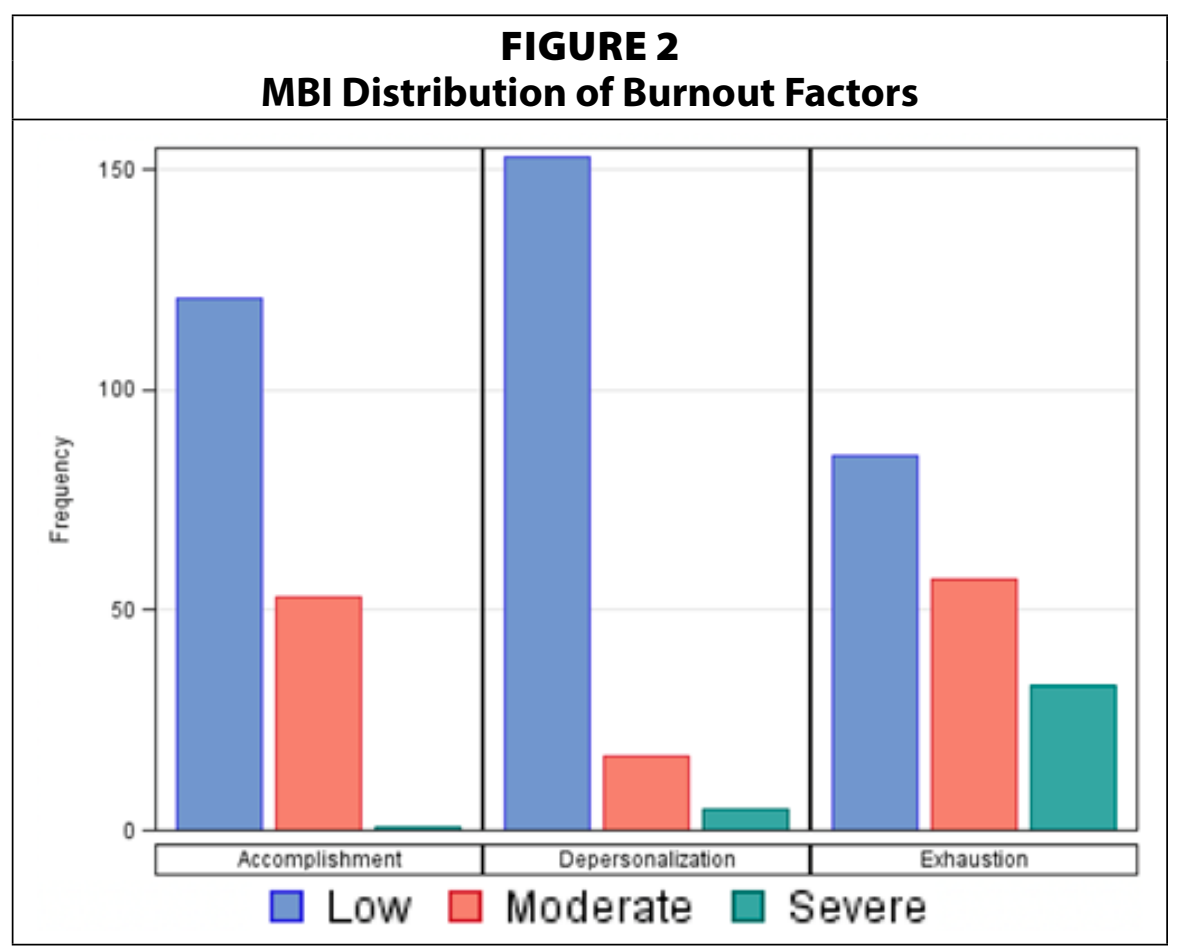
Specifically, low levels were reported most frequently across all three factors, followed by moderate levels, while reports of severe experiences were least frequent.

The combined results from both instruments show a significant disconnect of liaisons' lived experiences from their desire for both Reward and Community. Of all measurable categories, this mismatch best explains the population's frequently expressed sense of burnout. 
- How do self-identified role and level of seniority affect burnout?

The researcher first assessed how the population rated themselves with regard to their primary duties. Interestingly, Other outstripped both Instruction and Collections as the self-identified primary role in this sample, whereas the researcher anticipated Collections to be most frequently selected. Instruction was second highest in the list of primary responsibilities, as expected, as was the low percentage of liaisons who most closely identified with Data Management and Archives. Upon review of the raw data, the 58 responses in the Other category include 21 subjects who identify as primarily Reference/Research/ Outreach, 15 who identify as Management/

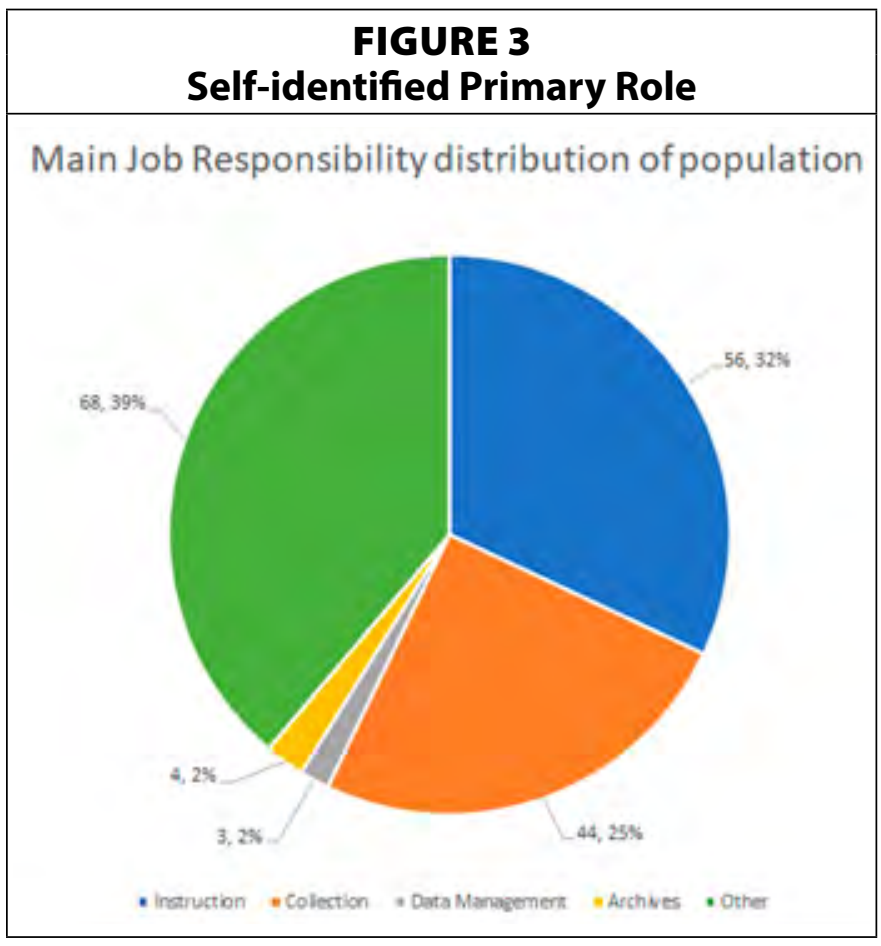
Administration, 6 who listed primary roles not mentioned by any other subject, and 14 who see Reference, Instruction, and Collections as so entwined into the single identity of liaison that they could not specify which was their primary role. The mix of these distinct roles within a single category indicates that it would be helpful if future research included Management, Reference/Research/Outreach, and Blend/ Mix as specific roles in the list of choices to better evaluate and understand those responses for which the relative importance of multiple responsibilities is indistinguishable.

In comparing the average burnout level for each role, Depersonalization is consistently the lowest of the three factors and sense of Personal Accomplishment is the highest, which draws a direct parallel with the finding for the entire sample. This correlation indicates that role has little overall effect on burnout.

When examining Emotional Exhaustion independent of the other factors, it is surprising that those indicating Data Management, Archives, or Other as their primary role outstrip the anticipated Instruction and Collection Development groups. One possible explanation is that, contrary to the initial hypothesis, regular interactions with populations outside the library stimulate Instruction and Collection Development groups by adding a larger human-focused component to their work, a component that is missing from the other three. Additionally, those who selected Other because they identified multiple duties as their primary role may experience greater burnout levels than those who identified a single focus, due to a sense that they continuously juggle multiple demands and responsibilities.

In gathering data about self-identified seniority in their organizations, it is clear that the majority of department liaisons see themselves as front-line personnel, presumably because they work directly with patrons rather than in a managerial role or in one at a remove from the public. The twelve respondents who did not indicate their seniority are likely to either not have understood the terminology or see themselves as a blend of front-line (such as patron-focused with direct interactions) and behind-the-scenes personnel in terms of activities including research and publication, selection duties, and other non-patron-oriented work. 


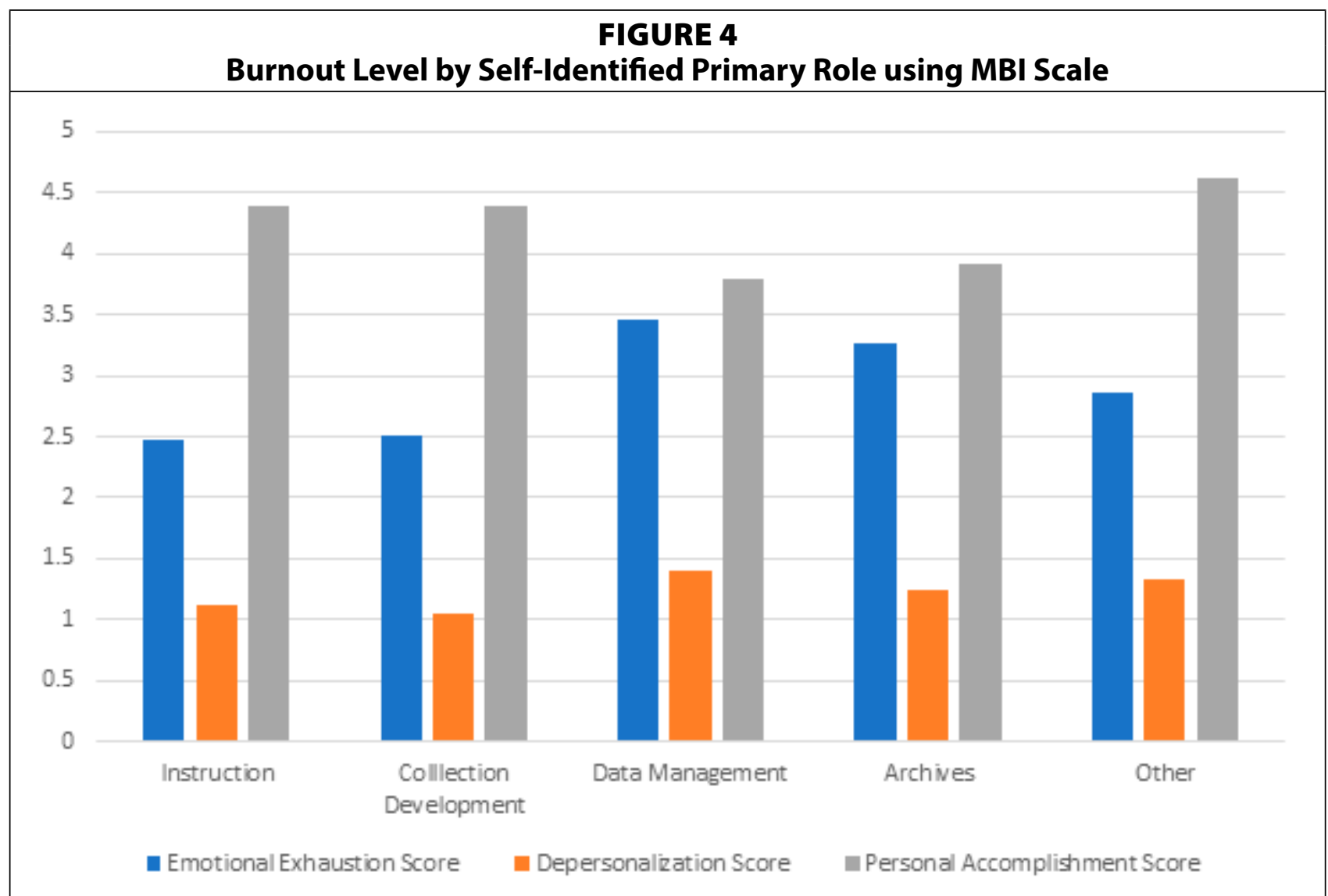

Contrary to the initial hypothesis, burnout levels vary irregularly over the position ranks rather than descending in a clear trend, from the front line with the highest reported burnout to upper management with the lowest. While the researcher anticipated that front-line personnel would rank highest in Emotional Exhaustion, they rank just behind intermediate management. Upon consideration, it is logical that those in intermediate management experience high levels of burnout, given the significant performance expectations over the wide range of responsibilities of these positions, frequently combined with needs for compliance with (and

\begin{tabular}{|l|c|}
\hline $\begin{array}{c}|c| \\
\text { TABLE 4 } \\
\text { Self-identified Seniority in } \\
\text { Organization }\end{array}$ \\
\hline Level & $\#$ \\
\hline Front-line & 103 \\
\hline Supervisor & 13 \\
\hline First Tier Management & 25 \\
\hline Middle Management & 19 \\
\hline Senior Management & 4 \\
\hline Not specified & 12 \\
\hline
\end{tabular}
some circumspection regarding) senior management's strategies and directions. In contrast, the front-line personnel have one or more buffers, in the form of direct supervisors and intermediate management, between themselves and senior management.

Senior management, as anticipated, ranked lowest in reported burnout on all three scales, while first-level management's and supervisors' relative scoring is the reverse of the initial hypothesis. Senior management reports the least burnout, with incidence increasing through supervisors, first-level management, and front-line personnel, with middle management reporting the highest level of burnout.

- How does time spent as a liaison affect burnout levels?

Burnout level as evidenced by Emotional Exhaustion and Depersonalization does not descend in a straight line based on time as a liaison, as was originally hypothesized. While the 


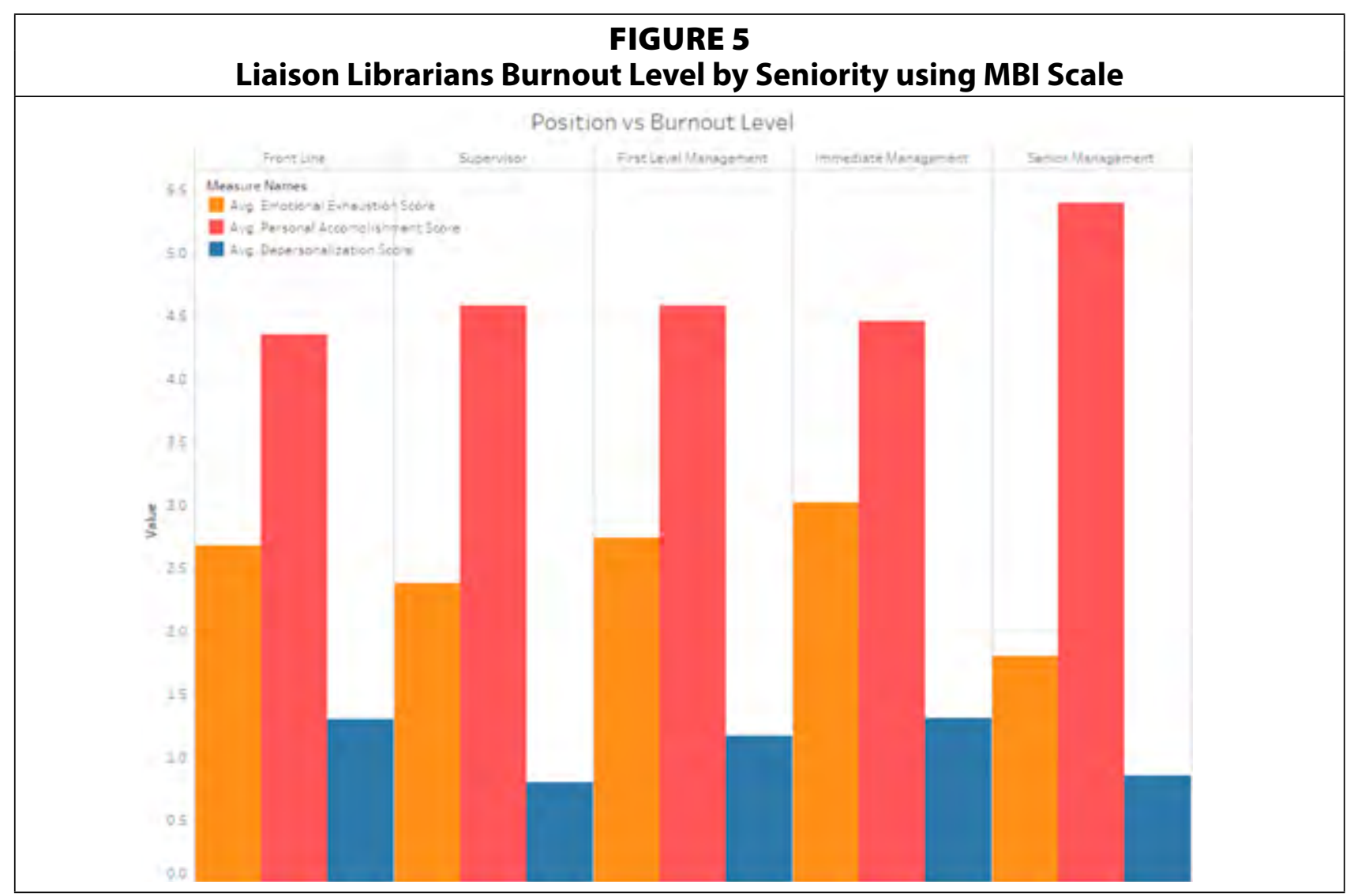

relative scores for Emotional Exhaustion, Depersonalization, and Personal Accomplishment remain at a constant, scores for each factor vary nonlinearly across time. As shown in figure 6, both Depersonalization and Personal Accomplishment drop steadily between the timespans covering one month to two years. At this point they diverge as Depersonalization increases, while Personal Accomplishment drops in the 3-5-year zone. In contrast, Emotional Exhaustion rises between the time a liaison assumes their role and 7 to 12 months thereafter, before dropping back down in years 1 to 2. From the 1-2-year measure, Emotional Exhaustion and Depersonalization run roughly parallel with each other through the rest of the measured period, whereas Personal Accomplishment rebounds between the 3-5-year and 8-10-year measures, then dips slightly for the next two time ranges before rising again at the 20-plus-year mark.

Unexpectedly, the 20-plus-years Emotional Exhaustion score rests in the middle of score range rather than at the high end, above $3-5$ years and below both 7-10 months and 3-5 years. In contrast, the logical explanation for low levels of Depersonalization for those with the longest time in their position is that those subjects are likely to be further along their vocational trajectory and may be experiencing end-of-career rewards such as acknowledgements and celebration of their accumulated accomplishments.

- How does time spent at an organization affect burnout levels?

Similar to burnout levels based on self-reported place in relative rank (such as seniority), burnout levels based on time in a specific organization were more random than expected. Recent hires show a decrease in Depersonalization and Emotional Exhaustion between their start date and the 1-2-year range, which can be explained by subjects' adaptation to their new workplace over their first two years of employment. Midrange lengths of employment at an organization rebound to relatively stable score levels near the high 


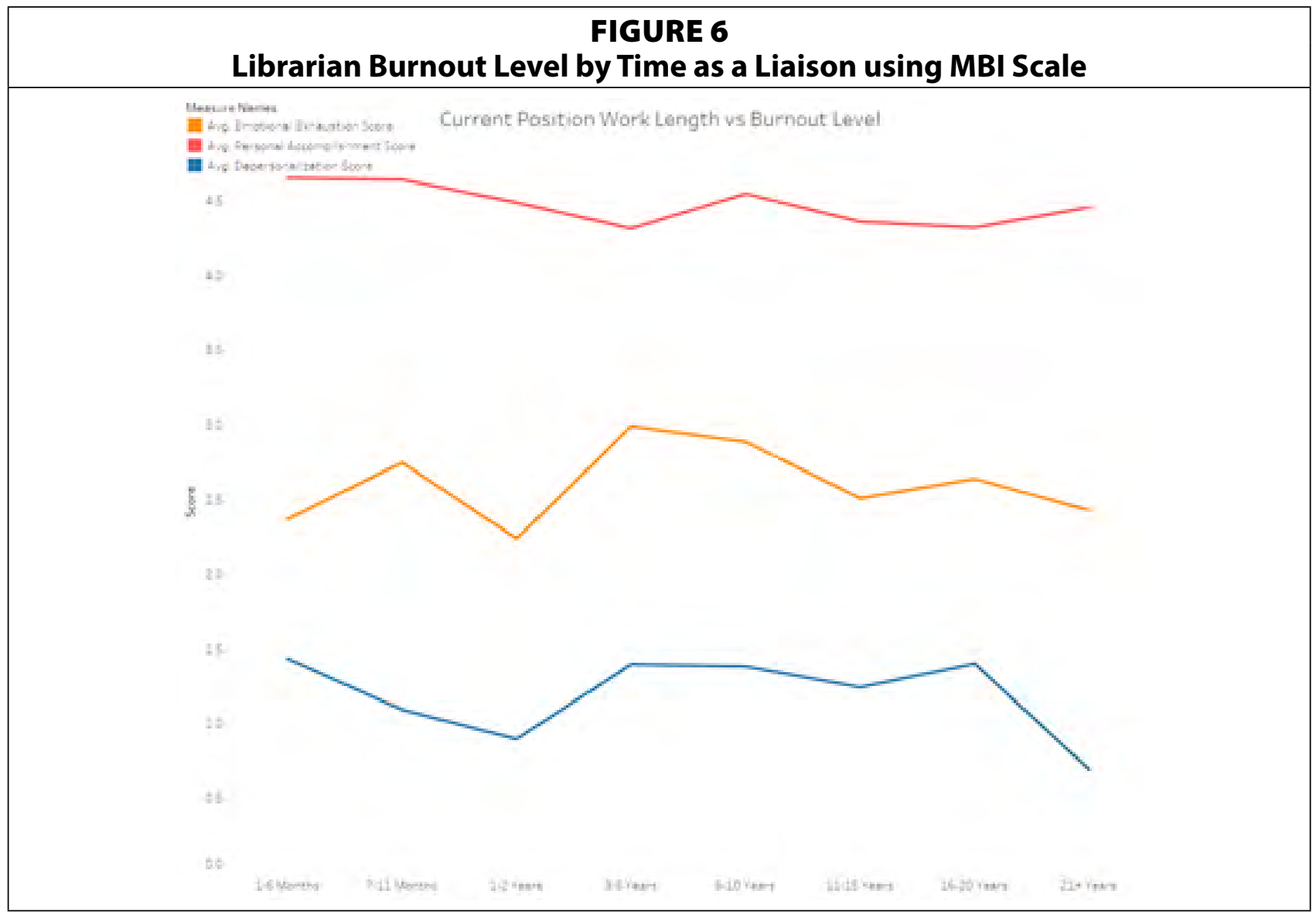

FIGURE 7

Liaison Burnout Level by Time in Organization using MBI Scale

Menicetionst.

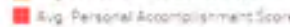

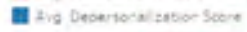

45

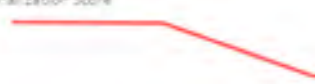

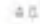

35




end of experienced Depersonalization and Emotional Exhaustion, while those with 16 or more years in one place have scores that drop to slightly lower Depersonalization and Emotional Exhaustion than those experienced at the entrance into a new organization. This last mirrors the experience of those with the most time as a liaison, likely for the same reasons as discussed above.

- Is there a gender effect on liaison librarian burnout?

To begin assessing gender effect on liaison burnout, the researcher first determined that, congruent to the larger librarian population, the majority -76 percent - of librarian liaisons identify as female, as compared to 21 percent male, and 3 percent unspecified.

When examining female versus male averages along the six measures in the AWS, males scored slightly higher than females across all measures; but, when comparing factors individually, each is similarly positioned across genders. Thus, the patterns of both male and female subjects indicate moderate to high matching of community, control, rewards, and values. Lower ratings on Fairness and more negative views of Workload are also the same for both genders.
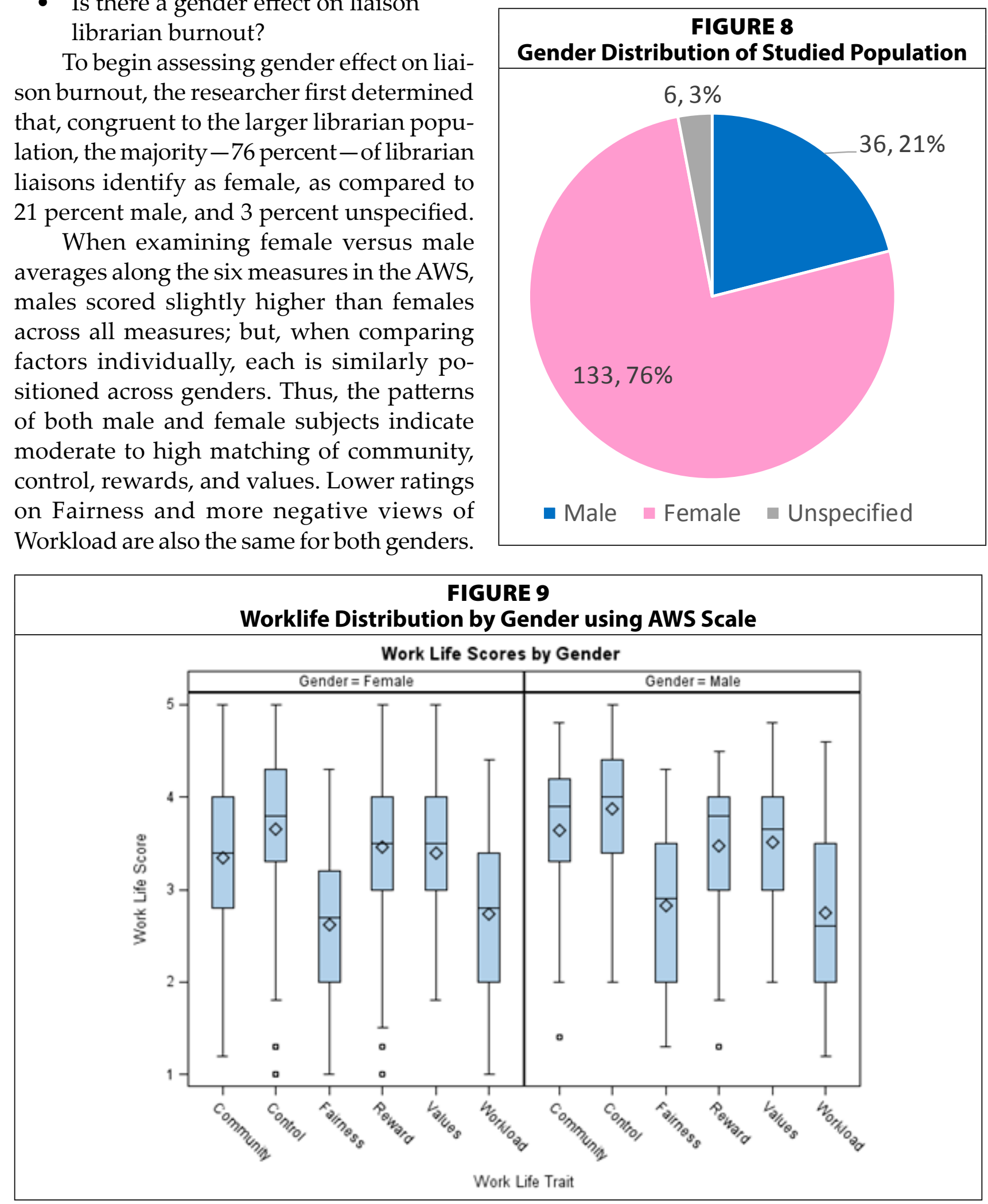

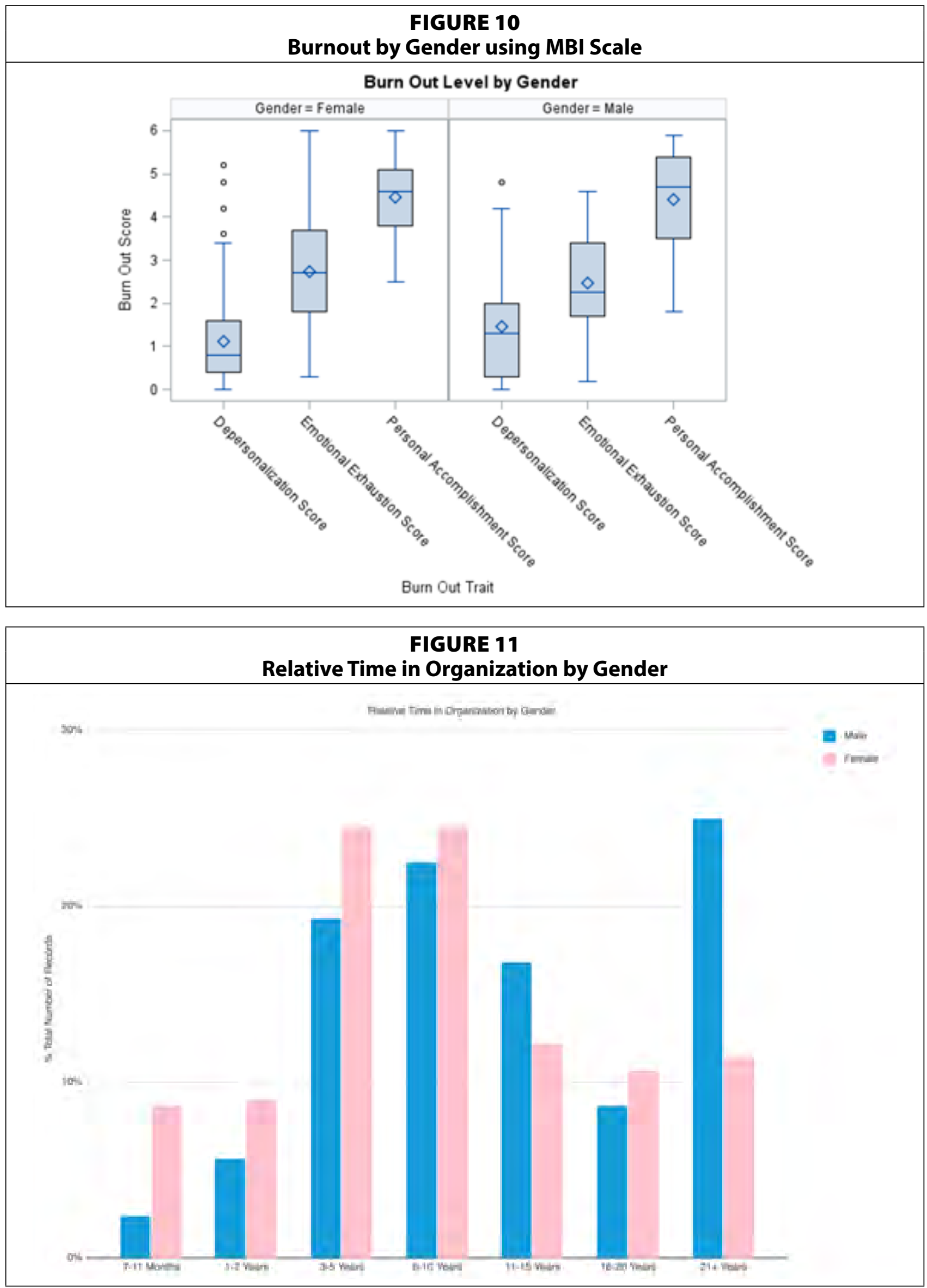
When assessing burnout scores by gender on the MBI scales, female scores on all three factors clustered more closely to the average than did the male scores, at the same time including more outliers. The relative scoring of Depersonalization as low, Emotional Exhaustion as moderate, and Personal Accomplishment as high was similar between both genders, which again aligns with the overall sample. A t-test on these data show no statistically significant difference between male and female scoring.

Interestingly, the sample data show that males spent significantly more time in an organization than females, even when taking into account the relative number of females versus males in the survey population. Females clustered heavily in the 3-10-year range, while males most often appeared in the 21-plus-year range. One possible explanation for this phenomenon is that, despite the predominance of women in librarianship, men hold the majority of upper management roles.

Most liaisons, both female and male, have been in liaison roles from 1 to 10 years. While the actual population numbers are significantly different between the genders, the pattern is similar during the first five timespans with the exception of the 0-6-month category, in which there were no males at all. Beginning with the sixth timespan, 11 to 15 years, the proportions flip and males exceed the number of females in liaison positions. One possible explanation, related to that above, is that more females take extended leave from work as part of their external roles as parents or caretakers than males do, thus shortening the timeframe in which females accumulate time in the liaison role.






\section{Conclusions}

Based on the initial findings it appears that, while under significant workload and with a low sense of fair treatment, liaisons are well-matched with their chosen profession in terms of worklife scoring regardless of gender, service time as a liaison, service time at a specific organization, self-identified rank, or self-identified primary responsibility or role.

The entire sample reported higher levels of Personal Accomplishment and lower levels of Emotional Exhaustion and Depersonalization on the MBI than anticipated. This is likely due to the high levels of career compatibility discussed above. That said, liaisons experience significant levels of Emotional Exhaustion and Depersonalization across all examined variables.

Combined, these findings indicate that there is a significant mismatch between the congruent individual values and stated professional principles, and liaisons' lived professional experiences. It would be worthwhile for those in administration at both the library and university levels to explore these disparities, with the goal of bringing work demands into alignment with core liaison and librarian values. ${ }^{37}$ This may prove a significant challenge, as an increasing number of institutions are adopting corporate models that emphasize the assessment of concrete outputs, such as annual research funding received and number of resources borrowed or used over a particular timespan. While this model has value in the modern global marketplace, it neglects some of the philosophical goals and values that are central to liaison identity. Such goals include building community-library rapport to encourage patron use of both online and physical spaces, teaching skills that translate both from one project to another and between academic and personal contexts (such as logical analysis or assessment of information), promoting positive town-gown relations via beyond-campus outreach programs, and facilitating equity of information access across their entire patron and community base.

These data can also reinforce individual liaisons' sense of compatibility of their career choice with their values and provide a framework in which they can better understand their perceived burnout in order to devise strategies to alleviate emotional exhaustion and depersonalization while continuing to bolster personal accomplishment. Furthermore, they can use this understanding as a platform from which they can create new ways to link abstract values with concrete assessment and measurement techniques. Alternatively, highlighting an incongruence that is likely to continue for the foreseeable future may motivate some liaisons to consider new career options, as well as individuals who are not currently liaisons to step into those roles as their own skills and values more closely align with those of modern academic libraries.

\section{Further Research}

As this is an initial survey of burnout in a specific niche of librarianship, there is much research yet to do, both within the library context and reaching outside librarianship to compare jobperson fit in other careers, as well as burnout experiences and mitigations strategies employed in other sectors to mitigate emotional exhaustion and depersonalization. Groups within the greater educator community are most likely to produce fruitful cross-sector information. Helping careers such as medicine and law enforcement may also provide some useful comparisons, although there are significant differences in the nature, severity, and duration of endemic stressors when compared with people in academia. 
Within the realm of academic librarianship, an assessment of the larger librarian population across all department and duty types - including but not limited to acquisitions, data management, information technology, and public services - would provide a better-rounded picture of burnout in the larger academic library community. More in-depth exploration of the relationship between professional rank and gender would provide insight into relative abilities to advance within academic library organizations, as would a closer look at the crosssection of rank and duty type.

Investigation into potential burnout mitigation strategies and their relative effectiveness would move this initial assessment from investigation to practical applicability, which would benefit both the individual and systemic levels of academic librarianship. Given the negative effects that burnout has on job performance, attendance, personal and professional relationships, and healthcare costs, it would be to organizations' advantage to implement burnout mitigation plans. These plans can, in turn, decrease costs associated with rapid employee turnover and significant absence due to illness, increase cohesive work toward overarching goals of both library and institution, and demonstrate employees' value to the organization, thus creating a positive feedback loop.

The formal assessment of burnout in academic librarianship is in its infancy. As a unique combination of service profession and academia, academic librarians merit significantly more study across many variables and in many configurations in order to establish greater understanding of job-person fit and burnout experience across the profession. These insights can be leveraged by academic library administration in creating policies and expectations that encourage and promote more abstract liaison librarian values, as well as developing new methods to connect liaison work with the data-driven goals and values of the greater organization.

\section{Notes}

1. Alexandra Michel, "Burnout and the Brain,"Observer Magazine 29, no. 2 (Feb. 2016), available online at https://www.psychologicalscience.org/observer/burnout-and-the-brain\#.WS7wRhPytBw [accessed 2 April 2019].

2. Christina Maslach and Susan E. Jackson, "The Measurement of Experienced Burnout," Journal of Organizational Behavior 2, no. 2 (1981): 101, doi:10.1002/job.4030020205; Flavio Muheim, "Burnout: History of a Phenomenon," in Burnout for Experts: Prevention in the Context of Living and Working, ed. Sabine Bährer-Kohler (Boston: Springer US, 2013), 41, doi:10.1007/978-1-4614-4391-9_3.

3. Christina Maslach, Susan E. Jackson, and Michael P. Leiter, Maslach Burnout Inventory Manual, 4th ed. (Menlo Park, CA: MindGarden, Inc., 2016), 1; "Christina Maslach," Social Psychology Network (last modified August 4, 2016), available online at http://maslach.socialpsychology.org/ [accessed 2 April 2019].

4. Michael P. Leiter and Christina Maslach, Areas of Worklife Survey Manual and Sampler Set, 5th ed. (Menlo Park, CA: Mindgarden, Inc., 2011), 2.

5. Maslach, Jackson, and Leiter, MBI Manual, 5-6, 12.

6. Maslach, Jackson, and Leiter, MBI Manual, 1.

7. Maslach, Jackson, and Leiter, MBI Manual, 4.

8. Leiter and Maslach, AWS Manual, 4.

9. Muheim, "Burnout: History of a Phenomenon," 38.

10. Muheim, "Burnout: History of a Phenomenon," 41.

11. Maslach, Jackson, and Leiter, MBI Manual, 1.

12. Maslach, Jackson, and Leiter, MBI Manual, 2.

13. Maslach, Jackson, and Leiter, MBI Manual, 15.

14. Denna L. Wheeler, Matt Vassar, Jody A. Whorley, and Laura L. B. Barnes, "A Reliability Generalization Meta-Analysis of Coefficient Alpha for the Maslach Burnout Inventory," Educational and Psychological Measurement 71, no.1 (2011): 237-39, doi:10.1177/0013164410391579.

15. Maslach, Jackson, and Leiter, MBI Manual, 3. 
16. Maslach, Jackson, and Leiter, MBI Manual, 8.

17. Leiter and Maslach, AWS Manual, 2.

18. Leiter and Maslach, AWS Manual, 2.

19. Leiter and Maslach, AWS Manual, 3-6.

20. Leiter and Maslach, AWS Manual, 1.

21. Leiter and Maslach, AWS Manual, 9.

22. Maslach, Jackson, and Leiter, MBI Manual, 15.

23. Mary Ann Affleck, "Burnout Among Bibliographic Instruction Librarians," Library and Information Science Research 18, no. 2 (1996): 172-73, doi:10.1016/S0740-8188(96)90018-3.

24. Deborah F. Sheesley, "Burnout and the Academic Teaching Librarian: An Examination of the Problem and Suggested Solutions," Journal of Academic Librarianship 27, no. 6 (2001): 447, doi:10.1016/S0099-1333(01)00264-6.

25. Aspasia Togia, "Measurement of Burnout and the Influence of Background Characteristics in Greek Academic Librarians," Library Management 26, no. 3 (2005): 136, available online at http://search.proquest.com/ lisa/docview/57603313/1423CC8FC8A66A763C0/1?accountid=17200 [accessed 2 April 2019].

26. Liz Farler and Judith Broady-Preston, "Workplace Stress in Libraries: A Case Study," Aslib Proceedings 64, no. 3 (2008): 225, doi:10.1108/00012531211244509.

27. Shelagh Genuis and Heidi Julien, “Emotional Labour in Librarians' Instructional Work," Journal of Documentation 65, no. 6 (2009): 934, doi:10.1108/00220410910998924.

28. Ellen I. Shupe, Stephanie K. Wambaugh, and Reed J. Bramble, “Role-Related Stress Experienced by Academic Librarians," Journal of Academic Librarianship 41, no. 3 (2015): 265, doi:10.1016/j.acalib.2015.03.016.

29. Miriam L. Matteson and Shelly S. Miller, "Emotional Labor in Librarianship: A Research Agenda," Library and Information Science Research 34, no. 3 (2012): 177, doi:10.1016/j.lisr.2012.02.003.

30. Miriam L. Matteson and Shelly S. Miller, "A Study of Emotional Labor in Librarianship," Library and Information Science Research 35, no. 1 (2013): 59, doi:10.1016/j.lisr.2012.02.003.

31. "The Value of Academic Libraries," The Society of College, National, and University Libraries (SCONUL) (last modified 2018), available online at https://www.sconul.ac.uk/page/the-value-of-academic-libraries [accessed 2 April 2019].

32. Louise Cooke, Michael Norris, Nial Busby, Thomas Page, Ginny Franklin, Elizabeth Gadd, and Helen Young, "Evaluating the Impact of Academic Liaison Librarians on Their User Community: A Review and Case Study," New Review of Academic Librarianship 17, no. 1 (2011): 23, doi:10.1080/13614533.2011.539096.

33. Maslach, Jackson, and Leiter, MBI Manual, 2.

34. Maslach, Jackson, and Leiter, MBI Manual, 22-23.

35. Leiter and Maslach, AWS Manual, 2.

36. "List of ARL Members," Association of Research Libraries, available online at www.arl.org/membership/ list-of-arl-members [accessed 8 August 2018].

37. "Core Values of Librarianship," ALA Issues \& Advocacy (last modified June 29, 2004), available online at www.ala.org/advocacy/intfreedom/corevalues [accessed 2 April 2019]. 